\title{
O momento "Bretton Woods" da Covid-19 e a cooperação monetária por bancos centrais
} CAMILA VILLARD DURAN ${ }^{I}$

\section{Introdução}

$\mathrm{N}$ O QUE SE refere à cooperação monetária internacional, o que a década de 1960, a crise global financeira de 2008 e a crise da Covid-19 de 2020 têm em comum? Em paralelo às organizações internacionais, instituídas pelo Acordo de Bretton Woods para disciplinar as relações financeiras globais, os três períodos históricos testemunharam a construção e a (atual) consolidação de um modelo jurídico particular de colaboração entre países. Esse modelo é sustentado por acordos entre bancos centrais, legalmente concebidos como uma rede de contratos bilaterais: os swaps cambiais.

Essa estrutura jurídica de cooperação bilateral entre autoridades monetárias tem como intuito assegurar liquidez de curto prazo em moeda estrangeira a bancos centrais, que precisam intervir em mercados financeiros em momentos de crise. Swaps cambiais são convenções jurídicas para troca de uma moeda nacional por outra, a uma taxa de câmbio à vista. Há um compromisso de reverter a transação em data futura, especificada em contrato (normalmente, entre um e noventa dias), recorrendo à mesma taxa de câmbio.

A rede de swaps é formada por autoridades nacionais monetárias, que se constituem efetivamente enquanto "comunidade epistêmica" (Haas, 1992), que compartilha valores e padrões técnicos de ação de política pública, ideias jurídicas e concepções econômicas sobre a gestão da moeda. Bancos centrais são agências especializadas, com mandato jurídico nacional, para responder a desafios monetários. Em tempos de crise, essas autoridades tendem a expandir ainda mais sua ação no espaço global, ativando relações com seus pares.

Em formato de rede e com alta flexibilidade, os contratos bilaterais de swap cambial foram reforçados e consolidados durante a crise da Covid-19. O argumento deste artigo é o de que eles tendem a se tornar um mecanismo permanente de resposta a distúrbios globais no centro do sistema monetário internacional, inclusive em substituição às instituições tradicionais de Bretton Woods - mas somente para os seletos países membros.

No pós-Covid-19, a consolidação desse mecanismo de cooperação, que serve como efetivo prestamista internacional de última instância para dólares 
americanos (por ora, a moeda internacional por excelência), representa um novo momento "Bretton Woods". ${ }^{1}$ O suporte jurídico não é mais um tratado, formalizado entre Estados-nação, com a criação correspondente de uma organização multilateral, que serve ao propósito específico de monitorar e gerenciar um conjunto de regras monetárias. O fundamento jurídico são contratos, de natureza mais flexível, que emolduram as relações entre autoridades nacionais (bancos centrais) e asseguram o fornecimento de dólares, em tempos de crise, aos membros da rede.

Esse modelo de cooperação não é, contudo, novo. Ele remonta à década de 1960, em que swaps cambiais foram originalmente empregados para sustentar o regime de paridade cambial, instituído pela primeira versão dos Acordos de Bretton Woods. Seu objetivo era facilitar a intervenção de bancos centrais no mercado de câmbio para a defesa da paridade acordada e o cumprimento de obrigações internacionais, cuja supervisão cabia ao Fundo Monetário Internacional (FMI). No tempo, contudo, os swaps cambiais caíram em desuso.

Durante a crise financeira global de 2008 e no ano de 2020, a rede de swaps cambiais foi reativada pela autoridade monetária americana, o Federal Reserve (Fed). O número de bancos centrais beneficiados foi expandido temporariamente, para além dos países de economias avançadas. O objetivo institucional contemporâneo da rede é melhorar as condições de liquidez em dólares americanos, no mercado financeiro global.

Swaps cambiais proporcionam a bancos centrais estrangeiros a capacidade de fornecer dólares americanos em suas próprias jurisdições. Swaps são, portanto, os mecanismos jurídicos de sustentação do mercado global de dólares, em que o Fed serve como efetivo prestamista de última instância, no topo de uma rede piramidal formada por contratos bilaterais. Os países, que têm acesso a esse tipo de acordo, não precisam acionar de imediato o FMI para ter acesso à moeda internacional. Swaps tornaram-se a primeira linha cooperativa de defesa monetária durante distúrbios econômicos.

Neste artigo, sustento dois argumentos principais. Primeiramente, identifico um fator jurídico que explica o novo momento Bretton Woods: a euromoeda. O suporte jurídico global para a moeda americana é um tipo de contrato internacional de depósito, o eurodólar. Em mercados financeiros altamente globalizados e conectados, o contrato de eurodólar serve para "emoldurar" as relações financeiras privadas, denominadas em dólares americanos. O eurodólar sustentou o processo de internacionalização da moeda americana e, atualmente, é o fator que explica sua persistência. Para assegurar o uso transfronteiriço do (euro)dólar em tempos de crise, um prestamista internacional precisa ser constituído.

O segundo argumento é o de que a resposta de bancos centrais em economias avançadas, onde circulam os eurodólares, foi a criação de uma rede de swaps centrada no Federal Reserve (FED), o emissor da moeda global. Essa rede, 
integrada em momentos de crise também por países de economia emergente, como o Brasil, está contribuindo fortemente para alterar a estrutura jurídica dos prestamistas internacionais. A crise da Covid-19 consolida uma mutação relevante na estrutura das relações monetárias globais: de organizações internacionais, criadas por Estados-nação, para mecanismos mais flexíveis de cooperação entre autoridades nacionais, organizadas em formato de rede hierárquica. Essa é a moldura do novo acordo de Bretton Woods.

O presente artigo está dividido em quatro seções. Para além desta introdução, a próxima seção apresenta a revisão da literatura e identifica o vazio do pensamento jurídico em explicar o papel do direito no processo de internacionalização de moedas nacionais e na sua persistência. A terceira seção explora a estrutura jurídica do prestamista de última instância para o sistema monetário internacional e de sua moeda internacional (o dólar americano). A rede de swaps cambiais serve como suporte ao desenvolvimento do mercado financeiro global, que se estrutura por meio de relações contratuais específicas (as euromoedas). A seção constrói uma análise jurídica dessas relações e da história da rede de swaps entre bancos centrais. Dados empíricos da formação e da expansão dessa rede, especialmente no contexto do pós-Covid, são explorados. Comentários conclusivos encerram o artigo.

\section{A revisão da literatura: em busca dos determinantes jurídicos de uma moeda internacional e de seu prestamista de última instância}

O prestamista internacional de última instância é o agente econômico que tem a capacidade (econômica e jurídica), bem como a intenção de assegurar o acesso a moedas globais, em momentos de crises de liquidez - ou seja, ele é um "estabilizador monetário" (Kindleberger; Aliber, 2011, p.229-56; Kindleberger, 2012, p.28, 291-8, 305; Lastra, 2015, p.540-1).

Neste artigo, identifico o direito como uma explicação importante para o surgimento e a persistência do dólar americano como moeda global. Em tempos de crise da Covid-19, o direito também é um fator explicativo para o novo momento Bretton Woods, caracterizado pelo reforço e pela expansão de uma estrutura jurídica alternativa de prestamista de última instância, que dá suporte ao dólar em momentos de estresse econômico.

Este artigo adota uma abordagem específica: a moeda como instituição jurídica (Desan, 2014). A moeda no mundo ocidental é uma instituição jurídica, uma forma de emoldurar e transferir valores, que depende de um conjunto de oportunidades e obrigações definidas pelo sistema político (ibidem). Embora, nessa referência, Desan (2014) refira-se à evolução da moeda nacional em nível local, o raciocínio não difere em âmbito global: a moeda internacional é uma instituição jurídica, uma forma legal de transferir valor e alocá-lo entre diferentes países. Há também um sistema político definindo um conjunto específico de direitos e obrigações entre agentes da economia internacional: por meio de 
tratados e outros arranjos jurídicos, inclusive de direito privado (isto é, contratos financeiros), Estados e agentes econômicos delimitam o arcabouço específico para canalizar fluxos de capital, precisamente por meio do uso da moeda internacional.

No contexto global, a moeda é essencialmente escritural e baseada em reivindicações contratuais de natureza creditícia. ${ }^{2}$ A qualidade desses instrumentos de crédito depende essencialmente da solvência do seu emissor, ou seja, das instituições financeiras, que estão no polo devedor de contratos de depósitos e outros títulos denominados em moeda estrangeira, negociados no mercado internacional.

A qualidade também depende da existência de um prestamista de última instância, que irá sustentar a segurança jurídica desses instrumentos financeiros em tempos de crise. No âmbito nacional, bancos centrais atuam como banqueiro dos bancos, fornecendo suporte financeiro, em sua própria moeda e evitando, assim, que problemas de liquidez se convertam em insolvência. Em âmbito global, é necessária uma entidade que seja capaz e esteja disposta a emprestar recursos em moeda estrangeira, em tempos de distúrbios econômicos. $\mathrm{O}$ arcabouço do prestamista internacional é, assim, estruturado pelo direito, por meio de diferentes arranjos jurídicos.

Seguindo o trabalho seminal de Strange (1971), a literatura em ciência política tem se focalizado sobretudo na avaliação dos determinantes políticos de uma moeda internacional, de forma a antecipar o futuro do dólar americano no contexto de pós-crises, ou ainda o surgimento do renminbi, a moeda chinesa, como um concorrente ao dólar em âmbito global (Prasad, 2017; Norrlof, 2014; Cohen; Benney, 2014; Kirshner, 2013; Otero-Iglesias; Steinberg, 2013; Cohen, 2013; Helleiner, 2008). No que se refere à literatura do direito monetário internacional, apesar de discussões relevantes sobre o que juridicamente constitui-se no poder monetário e na soberania estatal (Pistor, 2017; Lastra, 2015; Zimmerman, 2013), a pesquisa no direito ainda é pouco desenvolvida na avaliação das condições jurídicas para a internacionalização de uma moeda. Por internacionalização entendo o uso global de uma determinada moeda como meio de troca e de pagamento, unidade de conta e reserva de valor (Tabela 1 ).

Cohen (2013) identifica relações causais e ciclos de feedback entre o uso transfronteiriço de uma moeda e as capacidades políticas de um Estado emissor. Ele sustenta que a internacionalização da moeda é, em grande medida, um fenômeno de mercado, que reflete as preferências de agentes econômicos no comércio global e em mercados financeiros. A internacionalização seria, essencialmente, decorrente da demanda privada. No entanto, como as principais moedas de uso global tendem a ser aquelas emitidas por Estados, ${ }^{3}$ o poder derivado da internacionalização também se manifesta na relação global entre nações.

A capacidade de emitir um padrão monetário internacional (cf. Tabela 1) garante, pelo menos, quatro vantagens econômicas e políticas para Estados: 
senhoriagem, flexibilidade macroeconômica, reputação e alavancagem (Cohen, 2013). Em nível global, a senhoriagem é gerada sempre que estrangeiros adquirem e detêm quantias significativas da moeda nacional, ou direitos creditícios denominados nessa mesma moeda, em troca de bens e serviços. As aquisições de moeda representam o equivalente a um empréstimo subsidiado, ou sem juros, vindos exterior. Além disso, o uso transfronteiriço de uma moeda torna as restrições ao balanço de pagamentos menos rígidas, garantindo flexibilidade macroeconômica. A capacidade de financiar déficits com a própria moeda elimina entraves à expansão de gastos públicos, por meio das políticas fiscal e monetária. A reputação é outra importante vantagem: é uma modalidade de soft power. O uso global de uma moeda é uma fonte, por si só, de prestígio. Finalmente, o uso transfronteiriço de um padrão monetário pode ajudar Estados a exercerem influência sobre outras nações por meio do controle de acesso a mercados e recursos financeiros. A capacidade econômica e jurídica para a prestação de serviços financeiros internacionais garante poder relevante a Estados emissores. O acesso a ativos considerado como "seguros" é controlado por autoridades nacionais, no centro do sistema financeiro global (Pistor, 2017).

Tabela 1 - As funções institucionais de moedas globais

\begin{tabular}{l|l|l|l|l}
\hline \multicolumn{1}{c|}{$\begin{array}{c}\text { Funções } \\
\text { Monetárias }\end{array}$} & \multicolumn{1}{|c|}{ Meio de troca } & $\begin{array}{c}\text { Meio de } \\
\text { pagamento }\end{array}$ & Unidade de conta & Reserva de valor \\
\hline $\begin{array}{l}\text { Uso por agentes } \\
\text { privados }\end{array}$ & $\begin{array}{l}\text { Operações } \\
\text { no mercado } \\
\text { de câmbio }\end{array}$ & $\begin{array}{l}\text { Liquidação } \\
\text { de obrigações } \\
\text { comerciais } \\
\text { e financeiras }\end{array}$ & $\begin{array}{l}\text { Denominador } \\
\text { para contratos e } \\
\text { títulos de natureza } \\
\text { financeira e } \\
\text { comercial }\end{array}$ & $\begin{array}{l}\text { Moeda para } \\
\text { investimento }\end{array}$ \\
\hline $\begin{array}{l}\text { Uso por entidades } \\
\text { estatais }\end{array}$ & $\begin{array}{l}\text { Moeda usada } \\
\text { em intervenções } \\
\text { e também como } \\
\text { objeto de contratos } \\
\text { de swaps entre } \\
\text { bancos centrais }\end{array}$ & $\begin{array}{l}\text { Liquidação } \\
\text { de obrigações } \\
\text { jurídicas } \\
\text { internacionais }\end{array}$ & $\begin{array}{l}\text { Âncora para taxa } \\
\text { de câmbio }\end{array}$ & $\begin{array}{l}\text { Reserva } \\
\text { internacional } \\
\text { de bancos centrais }\end{array}$ \\
\hline
\end{tabular}

Fonte: Com base na obra fundacional de Benjamin Cohen (2013) e nas reflexões da autora sobre a função jurídica dos meios de pagamento (Duran, 2018).

Certamente, um Estado detém os mecanismos para controlar a emissão de sua própria moeda, mas o processo de criação da moeda não é monopólio exclusivo de um banco central. A moeda pública, emitida por autoridades monetárias, e a moeda privada, criada por instituições financeiras por meio da concessão de novos empréstimos, fazem parte de um "sistema monetário hierárquico integrado, tanto nacional como globalmente" (Pistor, 2017). A criação da moeda internacional não difere da moeda nacional: é compartilhada por bancos centrais, emissores de moedas transacionadas globalmente, e por instituições financeiras, por meio da formalização de relações creditícias internacionais com outros bancos e agentes econômicos. 
Para os Estados Unidos, a gestão de um padrão monetário internacional tem garantido um "privilégio exorbitante" a essa potência. ${ }^{4} \mathrm{O}$ uso generalizado de uma moeda confere alavancagem geopolítica e estratégica ao seu emissor. Ao mesmo tempo, também exige um certo grau de "benevolência" (Kindleberger, 2012), uma vez que o emissor é demandado a contribuir com a estabilidade financeira global e desempenhar o papel de prestamista de última instância em tempos de crise, sob pena de gerar distúrbios em seu próprio território. A alavancagem econômica e política pode vir acompanhada de desafios significativos para a gestão da política monetária nacional.

Desde a crise de 2008, a função de prestamista tem sido implementada, sobretudo, por uma rede de swaps em dólares americanos, formada por bancos centrais no centro do sistema monetário internacional. Esse modelo de cooperação também serviu como inspiração para a criação de redes de swaps, compartilhadas por países de economia emergente e em desenvolvimento, na periferia da ordem financeira global. Essas últimas têm servido, sobretudo, ao propósito de sustentar a internacionalização de moedas alternativas ao dólar (Duran, 2018; 2017a), mas ainda não foram ativadas em sua plena capacidade.

Perry Mehrling $(2015$, p.2) argumenta que os arranjos de swap são importantes, porque eles servem como "o suporte de um sistema monetário global, que continua sendo sobretudo um sistema de dólares americanos. [...] [O] desenvolvimento do mercado monetário privado internacional, e as redes de swaps entre bancos centrais, que dão suporte a esse mercado, estão criando um mecanismo concreto de elasticidade, que faz o sistema internacional de pagamentos funcionar em tempos de crise" (tradução livre).

Mas como e qual estrutura jurídica sustenta a função de prestamista em nível global? Qual é o papel do direito na formação e na persistência dessa função econômica? Em que medida o direito também é fator explicativo e constitutivo desse desenvolvimento global?

\section{O prestamista internacional de última instância em mercados} financeiros globalizados: a rede de swaps entre bancos centrais

Em 1944, os Acordos de Bretton Woods serviram ao propósito de estruturar a governança econômica global no pós-Segunda Guerra Mundial. ${ }^{5} \mathrm{O}$ tratado, que instituiu o Fundo Monetário Internacional (FMI), foi concebido como um sistema de moedas nacionais e os Estados detinham o controle sobre o movimento internacional de capitais. A primeira versão de Bretton Woods planejou uma ordem global em que diferentes moedas poderiam ser utilizadas em transações internacionais, sem qualquer hierarquia entre elas. A intenção original dos fundadores dos Acordos era permitir que Estados se valessem de moedas nacionais simetricamente em transações com agentes estrangeiros, de forma a manter a paridade da taxa de câmbio acordada em âmbito internacional (McKinnon, 1993). O intuito era garantir autonomia aos Estados na condução da política macroeconômica, uma significativa mudança intelectual se compara- 
da ao sistema internacional do padrão ouro, praticado por economias avançadas até a Primeira Guerra Mundial. Em tempos de crise, a instituição multilateral responsável pela assistência financeira a países com dificuldades em balanço de pagamentos seria o FMI.

As regras jurídicas e as práticas efetivas do sistema de Bretton Woods, contudo, diferiram substancialmente. O dólar americano tornou-se a principal moeda do sistema monetário internacional. Em termos práticos, o regime evoluiu para um "padrão dólar-ouro", na década de 1960 (McKinnon, 1993, p.15). Nessa ordem monetária, nascida principalmente das práticas do pós-Bretton Woods, o dólar e seu emissor, o FED, tornaram-se os motores para o funcionamento do sistema econômico global.

A partir da década de 1970, com o abandono da paridade cambial e a crescente liberalização do movimento de capitais, o dólar americano e o FED tornaram-se ainda mais relevantes para Bretton Woods. Como o valor do dólar deixou de estar vinculado ao ouro (o que era uma obrigação jurídica internacional), a política monetária do FED passou a influenciar de forma definitiva o valor dessa moeda em mercados globais e também sua demanda por outros países.

O dólar tornou-se, assim, a moeda internacional por excelência da segunda versão do Acordo de Bretton Woods, servindo como alicerce de um sistema financeiro altamente globalizado e em contínua expansão. O FMI, por seu turno, expandiu de forma significativa seus poderes e seu mandato a partir da década de 1970. Com o crescente número de crises financeiras internacionais, em um regime de câmbio flutuante, o Fundo ganhou mais poder por meio de seu papel de prestamista de última instância.

Nesse regime, contudo, o FMI tem proporcionado um mecanismo de desconto limitado para Estados: o limite são os recursos transferidos previamente por membros ao Fundo (geralmente, em forma de quotas) e que dependem de um acordo político significativo. Diferentemente de um banco central, o FMI não tem a capacidade jurídica e econômica de emitir a moeda demandada por países membros, sobretudo o dólar. ${ }^{6}$ O FMI é um prestamista de Estados-nação, e não de mercados financeiros.

As crises de 2008 e de 2020 revelaram que um prestamista, para mercados altamente globalizados e conectados, era necessário. A dificuldade era como replicar, juridicamente, a estrutura de um banco central nacional (o banqueiro dos bancos) em âmbito internacional, que sustentasse, notadamente, o eurodólar.

\section{O suporte jurídico do mercado internacional de dólares americanos: as euromoedas}

Semelhante à esfera doméstica, o ambiente monetário internacional é um sistema baseado em relações contratuais de crédito. Desde sua criação na década de 1960, o mercado global de "euromoedas" tem garantido o fornecimento de moeda privada internacional (McKinnon, 1969; 1977; Kindleberger, 1981; Carreau, 1998; 1988), uma estrutura jurídica que ganhou importância com a 
crescente globalização das finanças. Uma euromoeda é uma moeda mantida em instituição financeira no exterior, fora da jurisdição de seu Estado emissor. O eurodólar é a moeda mais importante negociada internacionalmente. Ela é seguida de longe pelo euro e por outras moedas globais, como a libra esterlina, o iene japonês ou o franco suíço.

O prefixo "euro" é enganoso. Trata-se apenas da origem dessa moeda: o mercado de euromoedas foi inicialmente criado por banqueiros londrinos, na década de $1950 .^{7}$ O prefixo significa apenas que a moeda é objeto de um contrato de depósito em um banco, localizado em um país em que essa moeda não tem curso legal. ${ }^{8}$

O mercado de euromoedas é um arcabouço jurídico de direito privado e descentralizado, em que moedas globais e empréstimos em moedas estrangeiras são negociados de forma contínua. Esses mecanismos contratuais deram origem a um mercado monetário e financeiro global, que recorre principalmente ao padrão monetário americano e se denomina como o mercado de "eurodólares". O mercado de eurodólares é o mais importante do mundo, que produz e sustenta a liquidez em dólares americanos no exterior. Por meio dele, agentes econômicos, inclusive agências públicas, podem ter acesso a instrumentos financeiros, denominados em dólares, para investir ou liquidar suas obrigações, fora dos Estados Unidos.

Ainda que economistas sustentem que o mercado de euromoedas é um "mercado não regulamentado" (McKinnon 1969; 1977), a “desregulamentação" é um termo impreciso. Não se trata da ausência de regulamentação, mas sim a delegação regulatória implícita a diferentes agentes, tipicamente não estatais (as instituições financeiras e seus mecanismos contratuais), que, dentre outros aspectos, gozam da proteção pelo Estado, em cujo território relações jurídicas foram constituídas (Pistor, 2013).

A escolha de uma moeda não é apenas a expressão da confiança social em determinado padrão monetário. É também a aceitação social de uma logística específica de reivindicações contratuais, que sustentam e condicionam relações monetárias, inclusive em âmbito internacional. Relações econômicas somente podem ser compreendidas a partir de um conjunto específico de conceitos jurídicos, como propriedade e contratos, e as instituições correspondentes, que sustentam os direitos e as obrigações decorrentes dessas relações (Hodgson, 2015), como o Poder Judiciário e os órgãos da Administração Pública.

Inicialmente, o mercado de eurodólares era um mercado de depósitos de curto prazo, para liquidação em até três meses (Hirsch; Oppenheimer, 1976, p.663). A década de 1960, contudo, testemunhou o início de um mercado de financiamento internacional, com bancos em diferentes países dando suporte a emissão de títulos denominados em dólares por governos, autoridades públicas e multinacionais, com vencimentos de até quinze anos (ibidem). Esses títulos foram chamados de eurobonds, ou euro-obrigações. 
A euro-obrigação é uma dívida de médio ou longo prazo, denominada em moeda estrangeira. É um ativo internacional: o título representa uma reivindicação contratual em mercados financeiros. Tanto os eurodólares como as euro-obrigações contribuíram de forma decisiva para a internacionalização da moeda americana, uma vez que permitiram agentes econômicos liquidar suas obrigações, bem como deter investimentos em dólares, no exterior.

Carreau (1998) identifica os dois regimes jurídicos que estruturam a euromoeda: a lex contractus e lex monetae. A euromoeda é um contrato internacional de depósito, cujo objeto é uma moeda estrangeira. O regime jurídico de direito privado, do país onde se encontra a instituição financeira (a depositária), estrutura legalmente as euromoedas detidas por agentes econômicos (depositantes) e define o conjunto específico de direitos e obrigações daí decorrentes. A credibilidade e o valor dos contratos financeiros dependem de sistemas jurídicos formais, que tenham a capacidade de reivindicar com autoridade os direitos e as obrigações das partes contratuais, ou de recorrer, quando necessário, a seus poderes coercitivos para a execução de tais reivindicações (Pistor, 2013). A Europa é a região em que o mercado de euromoedas está mais desenvolvido: a lex contractus de países europeus é fortemente sustentada por instituições públicas, ou seja, tribunais e administração.

Simultaneamente, a euromoeda é submetida à lex monetae do Estado emissor, ou seja, o regime jurídico de direito público, que regula os usos e o valor da moeda nacional, que serve de lastro à euromoeda. A soberania monetária de Estados, ou seja, o poder de emitir e regular sua moeda, é convencionalmente reconhecida pelo direito internacional público (Lastra, 2015, p.14-15).

Carreau (1998, p.353) sustenta que a condição institucional para que uma moeda seja, de fato, internacionalizada é a possibilidade jurídica de sua conversão (conversibilidade), tanto em transações relativas à conta de capital e como de conta corrente. No âmbito internacional, Bretton Woods prevê somente a obrigação internacional, para membros do FMI, de garantir a conversibilidade no que se refere a transações em conta corrente (portanto, liquidação de obrigações de natureza comercial). ${ }^{9}$

Com exceção dos membros da Organização de Cooperação e de Desenvolvimento Econômico $(\mathrm{OCDE}),{ }^{10}$ não há obrigação de natureza multilateral de conversibilidade da moeda nacional para transações relativas à conta de capital. É, principalmente, a lex monetae do Estado emissor que estrutura a conversibilidade da moeda e determina as possibilidades jurídicas de operações financeiras internacionais denominadas nesse ativo. Por exemplo, países que adotam controles de capital podem restringir a capacidade de agentes econômicos domésticos em adquirir ativos estrangeiros, ou a capacidade de estrangeiros em adquirir ativos domésticos. Trata-se de restrições típicas às transações da conta de capital. Até o presente, contudo, as moedas transacionadas globalmente são juridicamente conversíveis em ambas as modalidades de transações, com exceção do renminbi. ${ }^{11}$ 
A China, em sua estratégia de internacionalização, claramente distingue a euromoeda $(\mathrm{CNH})$, negociada em mercados internacionais, de sua moeda nacional $(\mathrm{CNY})$. Essa distinção viabiliza a imposição de restrições, assegurando maior controle sobre o processo de criação da moeda internacional e sua conexão com mercados locais. Essa qualidade diferencia fortemente o desenho jurídico para a internacionalização da moeda chinesa de outras moedas globais, como o dólar americano, o franco suíço ou a libra esterlina. Essas últimas têm conversibilidade total e nenhuma distinção entre a euromoeda e seu lastro, a moeda nacional. Somente em tempos de crise, os agentes econômicos "percebem" a diferença fundamental existente entre ambas as moedas ${ }^{12}$ e os problemas institucionais relacionados ao acesso ao prestamista de última instância.

\section{Swaps cambiais entre bancos centrais: história e prática jurídicas}

$\mathrm{Na}$ década de 1960, o sistema monetário internacional caracterizou-se pelo desenvolvimento crescente do mercado de euromoedas, que, por sua vez, sustentou a internacionalização da indústria bancária. O eurodólar, legalmente concebido como um contrato de depósito internacional em dólares americanos, ganhou importância.

As técnicas jurídicas são fatores explicativos importantes para a internacionalização do dólar. $\mathrm{O}$ mercado de eurodólares passou a demandar, para seu desenvolvimento institucional, um prestamista de última instância com capacidade de fazer descontos ilimitados nessa moeda, sustentando-a em tempos de crise. O renascimento de uma rede de swaps de moedas entre bancos centrais, no centro do sistema monetário global e com o FED em seu topo, foi o resultado dessa demanda, que se consolidou sobretudo a partir da crise financeira de 2008.

Juridicamente, a estrutura de um swap cambial é a seguinte: um banco central $\mathrm{X}$ vende um valor específico de sua própria moeda ao banco central Y (o FED, por exemplo), em troca da moeda de Y (o dólar americano), a uma determinada taxa de câmbio. Em regra, a taxa de câmbio implica uma taxa de juros a favor do banco central $\mathrm{Y}$, a quem cabe fornecer a divisa demandada pelo banco central X. O contrato prevê que o banco central X concorda em recomprar sua própria moeda em uma data futura especificada, à mesma taxa de câmbio.

O banco central X mantém uma conta de depósito no banco central Y para operacionalizar a troca da moeda, e vice-versa. Após a primeira transação financeira, o banco central X pode usar a moeda de $\mathrm{Y}$ para emprestar a bancos e outras instituições financeiras de sua própria jurisdição. Todas as transações de swap são representadas como lançamentos contábeis em cada um dos bancos centrais.

$\mathrm{O}$ efeito econômico de um acordo de swap é que a moeda de $\mathrm{X}$ serve como garantia para o empréstimo da moeda de Y. No entanto, a vantagem jurídica de um contrato de swap, em contraste com um contrato de empréstimo com garantia, é transferir temporariamente a propriedade da moeda de $\mathrm{X}$ (do banco central emissor para o banco central $\mathrm{Y}$ ). Em caso de inadimplência, a moeda de $\mathrm{X}$ é um ativo do banco central $\mathrm{Y}$ e pode ser usada para compensar as perdas incorridas. 
Swaps cambiais entre bancos centrais não são invenções recentes. Em 1920, swaps de moeda foram operacionalizados ocasionalmente por autoridades monetárias, de forma ad hoc (Toniolo, 2005, p.17, 386). ${ }^{13}$ Mas foi sobretudo a década de 1960 que testemunhou o surgimento da rede de swaps entre bancos centrais (Moessner; Allen, 2010, p.25-27; Kindleberger; Aliber, 2011, p.24950; Toniolo, 2005, p.381-388; Gold, 1984, p.263-264; Coombs, 1976, p.83, 232; Hirsch, 1967, p.349-53). O Banco de Pagamentos Internacionais (Bank for International Settlements - BIS) foi uma das contrapartes. O "Acordo de Swap da Basileia", como foi denominado, administrou e sustentou o sistema de paridade fixa, criado pela primeira versão de Bretton Woods (Carré; Le Maux, 2020).

A convenção consistia em uma série de acordos bilaterais entre o BIS, o FED e os principais bancos centrais europeus. ${ }^{14} \mathrm{O}$ arranjo visava conter ataques especulativos às moedas europeias e sua paridade cambial, definida pelo sistema de Bretton Woods. Especialmente, para o FED, tratava-se de sustentar a paridade do dólar em relação ao ouro. O FED recebia a moeda de autoridades europeias, com as quais poderia resgatar os dólares americanos detidos por elas. De outro modo, essas moedas poderiam ser apresentadas diretamente ao FED para conversão em ouro (Gold, 1984, p.263-4). Uma “corrida” ao ouro poderia colocar em risco a confiança no funcionamento do sistema monetário internacional da época e a robustez das reservas cambiais do FED. Os swaps foram, assim, concebidos como o mecanismo jurídico de cooperação, que reduzia a pressão sobre o FED e a obrigação correspondente dos Estados Unidos em converter dólares em ouro a um preço fixo, estabelecida por tratado internacional. ${ }^{15}$

A implementação desse Acordo era percebida por banqueiros centrais como uma forma eficaz de cooperação monetária global, que poderia lidar com "qualquer ameaça” ao regime cambial de Bretton Woods (Toniolo, 2005, p.383). Em contraste, o jurista Joseph Gold (1984, p.264), antigo advogado do FMI, afirmava que os membros do Fundo viam as medidas do Acordo de Basiléia como "placebos e obviamente não remédios” para a sustentabilidade do sistema de Bretton Woods. De fato, banqueiros centrais não puderam salvar o abandono do regime cambial de paridade fixa em 1971, feita de forma unilateral pelos Estados Unidos.

Com o fim do padrão dólar-ouro e o fortalecimento e a expansão das funções do FMI como prestamista internacional de última instância, a primeira rede de acordos de swaps expirou, oficialmente, em 1998. O comitê de política monetária do FED, o Federal Open Market Committee (FOMC), reconheceu que a cooperação bilateral estava em desuso, devido à existência de "regimes [...] bem estabelecidos para a cooperação monetária internacional" (tradução livre ). ${ }^{16}$ Com a expansão das funções e dos membros do FMI, o FOMC permitiu que swaps entre o FED e um distinto grupo de bancos centrais, sobretudo europeus, caducassem após reconhecidos quinze anos de abandono. 


\section{As crises de 2008 e da Covid-19: o novo momento Bretton Woods}

Em um sistema financeiro altamente globalizado e desenvolvido, o FMI, como prestamista internacional de última instância, não é capaz de oferecer desconto ilimitado em dólares americanos. Ademais, a flexibilidade e a rapidez demandadas para resposta a crises globais não se adequam com o processo de tomada de decisão política pela burocracia do Fundo, na concessão de recursos a países membros. O FMI é prestamista de Estados-nação, e não de agentes de mercados.

Em termos de cooperação monetária global, um prestamista internacional deve ser capaz e estar disposto a dar acesso à moeda internacional, durante crises de liquidez. Para assegurar sua credibilidade, do mesmo modo que em ambientes nacionais, não deve haver limite para a concessão de crédito (Hawtrey, 1932). Portanto, apenas bancos centrais, emissores de moedas globais, podem fornecer acesso ilimitado à liquidez internacional.

Bancos centrais podem emprestar livremente, uma vez que são entidades financeiras que têm a capacidade de expandir seu balanço patrimonial sem restrições institucionais. Elas têm o poder jurídico de emitir sua própria moeda, ou seja, a moeda nacional. Autoridades monetárias podem, na prática, acumular perdas ou operar com patrimônio líquido negativo. $\mathrm{O}$ uso expansivo de seu balanço não afeta a criação da moeda, nem requer eventual capitalização. ${ }^{17} \mathrm{Em}$ contrapartida, os desenhos institucionais alternativos, para o exercício das funções de prestamista, devem considerar sua capacidade e sua credibilidade em fornecer liquidez em tempos de crise, sem desfrutar do poder jurídico de bancos centrais. Legalmente concebido como um fundo, o FMI tem restrições institucionais significativas para apoiar países membros em tempos de crise.

Assim como na esfera financeira doméstica, o arranjo jurídico global, que sustenta o mercado de eurodólares, é centralizado por bancos centrais. Em particular, o eurodólar possui uma estrutura hierárquica de prestamista: a rede de swaps cambiais, estabelecida por bancos em economias avançadas, foi desenhada para fornecer suporte financeiro ilimitado a suas contrapartes, no centro do sistema monetário internacional. Swaps temporários e de valor limitado foram estendidos a bancos centrais em economias emergentes para responder a crises imediatas, primeiro, em 2008 e novamente em 2020.

Durante a crise de 2008, o FED tornou-se, de fato, o prestamista internacional de última instância, e recorreu à rede de swaps cambiais para dar suporte financeiro a seus pares (Aizenman; Pasricha, 2010; Allen; Moessner, 2010; Moessner; Allen, 2010; McDowell, 2012; Chey, 2012; Broz, 2015). Em 2020, essa estrutura foi reativada e passou a se configurar como um mecanismo perene de cooperação monetária.

Do ponto de vista jurídico, a rede de swap em dólares tem uma forma institucional particular: ela se formaliza por meio de uma série de contratos bilaterais entre autoridades monetárias. $\mathrm{O}$ banco central americano sustenta que $\mathrm{o}$ 
fundamento legal para a formalização de swaps é a seção 14 do Federal Reserve Act, que dá autoridade ao FED para conduzir operações de mercado aberto.

Os swaps cambiais revelam um alto grau de confiança entre bancos centrais. O contrato com o FED, que foi formalizado com seus cinco maiores parceiros (Banco Central Europeu - BCE, Banco da Inglaterra, Banco do Japão, Banco Nacional Suíço e Banco do Canadá), não tem mais do que sete páginas e doze cláusulas. ${ }^{18}$ Não há sequer previsão jurídica para solução de controvérsias. Pode-se contrastar esse modelo de contrato com as extensas e exaustivas 31 cláusulas, e incontáveis seções, do Convênio Constitutivo do FMI, que conta com a adesão de 189 países.

Em comparação com a década de 1960, o que foi distinto durante as crises de 2008 e de 2020 foi a rápida proliferação de swaps entre bancos centrais, os volumes significativamente maiores (se usados em toda a sua extensão, há a possibilidade de ultrapassar significativamente os recursos do próprio FMI), e sua extensão temporária para economias de mercado emergente.

O Gráfico 1 revela onde estavam localizados os mercados mais relevantes para os eurodólares e a correspondente demanda por um prestamista de última instância para responder à crise de 2008. O BCE recebeu apoio significativo do FED.

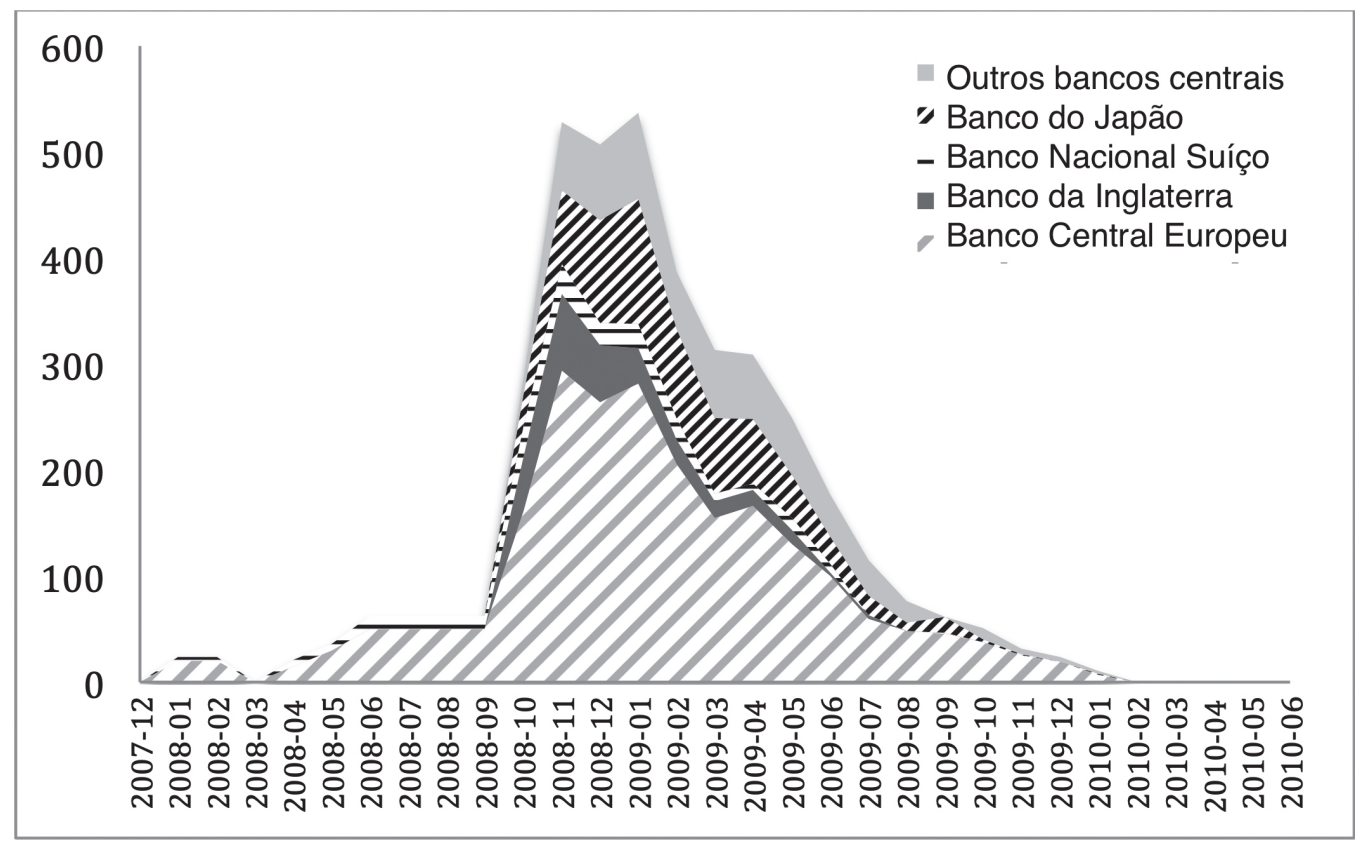

Fonte: Carré e Le Maux (2018, p.10).

Gráfico 1 - Montantes semanais para as linhas de swap de dólar alocados pelo FED a bancos centrais (dezembro de 2007 - maio de 2010, em bilhões de dólares). 
No imediato pós-2008, os contratos de swap foram concebidos como arranjos meramente temporários e limitados, inclusive para os cinco bancos centrais parceiros do FED. À medida que a crise se aprofundava, os swaps passaram a ser autorizados em quantias ilimitadas (Carré; Le Maux, 2018). De forma pontual, também foram disponibilizados swaps em dólares para as autoridades monetárias da Austrália e da Suécia (até US\$ 10bi), da Noruega e da Dinamarca (até US\$ 5bi), da Nova Zelândia (até US\$ 15bi), e para seletos países de economias emergentes (até US\$ 30 bi cada), como Brasil, México, Coreia do Sul e Cingapura (Duran, 2015; McDowell, 2019; Henning, 2015).

No entanto, em 2013, o FED e os cinco maiores bancos centrais do mundo (BCE, Banco da Inglaterra, Banco do Japão, Banco Nacional Suíço e Banco do Canadá) declararam publicamente que os acordos seriam convertidos em permanentes, "isto é, acordos que permanecerão vigentes até novo aviso. [...] Esses acordos permitem o fornecimento de liquidez em cada uma das jurisdições, em qualquer uma das cinco moedas estrangeiras, caso dois bancos centrais, em um acordo de swap bilateral, julguem que as condições de mercado justifiquem tal ação" (tradução livre, Comunicado de impressa do FED, 31 de outubro de 2013). ${ }^{19}$

Em 2020, para responder à crise da Covid-19, a estrutura de cooperação monetária apoiou a ação de bancos centrais, respondendo ao novo estresse no mercado de eurodólares. Os swaps permanecem um mecanismo de desconto ilimitado, persistente e centralizado pelo FED. Os valores efetivamente mobilizados foram bastante expressivos, ainda que, por ora, sejam menores do que a crise de 2008 (Gráfico 2).

Em 19 de março de 2020, o FED anunciou expansão da rede de swap. Esses novos arranjos, limitados a determinado valor, foram reativados novamente com os bancos centrais da Austrália e da Suécia (até US\$ 60 bi cada), Dinamarca, Noruega e Nova Zelândia (até US\$ 30 bi cada), e os países de economia emergente, Brasil, México, Cingapura e Coreia do Sul (até US\$ 60 bi cada). ${ }^{20}$ Os volumes disponibilizados foram ampliados substancialmente comparativamente a 2008.

Em outro movimento inventivo, em 31 de março, com o objetivo de apoiar o mercado de eurodólares, o FED anunciou o estabelecimento de um acordo de recompra (repo) destinado a bancos centrais estrangeiros, cujas reservas fossem constituídas por títulos do Tesouro americano (o "Fima Repo Facility"). Um acordo de recompra é um contrato de curto prazo, que envolve a venda de títulos (nesse caso, os títulos do Tesouro dos Estados Unidos) com um compromisso de recompra futura, a um preço mais elevado.

Da perspectiva econômica, bancos centrais precisam de ativos percebidos como seguros, denominados em moedas globais, para armazenar riqueza. As autoridades monetárias adquirem esses instrumentos como reserva, pois seu objetivo principal é financiar desequilíbrios e flutuações cambiais, notadamente em 
tempos de crise, dando suporte a agentes econômicos sediados em suas próprias jurisdições e endividados em moeda estrangeira. Títulos do Tesouro americano servem a esse fim.

Na prática, o Fima permite que bancos centrais convertam seus títulos do Tesouro em dólares americanos no overnight. O efeito econômico é o seguinte: quem vende os títulos está, efetivamente, tomando um empréstimo em dólares; e a outra parte (o FED) está concedendo suporte financeiro, tendo os títulos como garantia. Segundo o FED, o Fima é mais um instrumento para beneficiar "a economia dos Estados Unidos, [...] bem como promover o papel internacional do dólar". ${ }^{21}$

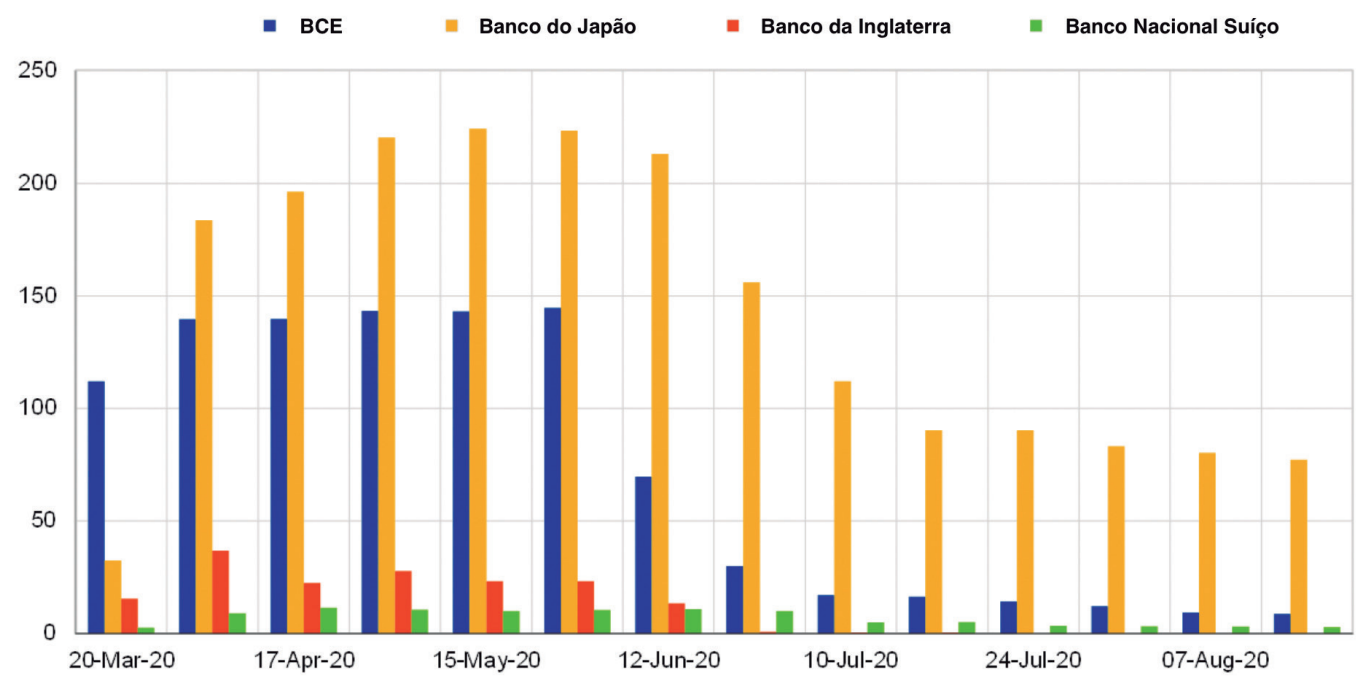

Fonte: Panetta e Schnabel (2020).

Gráfico 2 - Saldo das operações de swaps em dólares americanos para bancos centrais selecionados (em US\$ bilhões).

Os bancos centrais em economias emergentes, que podem se beneficiar do Fima, são aqueles que já detêm reservas cambiais constituídas por títulos do Tesouro americano, mas não dispõem, eventualmente, de acesso aos swaps com o Fed. A Tabela 2 identifica os países de economias emergentes, que poderiam se beneficiar desse novo instrumento.

A crise da Covid-19 aponta para o mesmo padrão jurídico de cooperação monetária global: no centro do sistema monetário global, uma rede formada por bancos centrais, que serve como prestamista internacional para agentes econômicos atuando no mercado de eurodólares. Os acordos Fima, de forma a complementar à rede de swaps, foram adicionados para apoiar bancos também em economias emergentes, que detenham reservas consideráveis em dólares americanos, porém sem acesso aos swaps com FED.

A característica jurídica fundamental desses acordos é a sua base contratual. No centro do sistema monetário internacional, as relações monetárias, so- 
bretudo no pós-Covid-19, tendem a se estruturar como convenções contratuais creditícias, suportadas por autoridades monetárias, e não mais por acordos políticos entre Estados intermediados por organizações internacionais. Esse desenvolvimento indica uma perda da centralidade do FMI para a resolução de crises no centro do sistema global, porém sua continuidade no suporte à periferia da ordem monetária - ou seja, a países em desenvolvimento com mercados financeiros menos desenvolvidos e menos conectados ao mercado de eurodólares.

Tabela 2 - Banco central em economias emergentes: reservas em moeda estrangeira e títulos do Tesouro dos Estados Unidos (em US\$ bi)

\begin{tabular}{|c|c|c|c|}
\hline \multirow[t]{2}{*}{ Países } & \multicolumn{2}{|c|}{ Títulos do Tesouro americano em reserva } & \multirow[t]{2}{*}{$\begin{array}{c}\text { Reservas cambiais } \\
\text { (total) }\end{array}$} \\
\hline & US\$ bi & $\begin{array}{c}\% \text { das Reservas } \\
\text { cambiais }\end{array}$ & \\
\hline China & $1,078.6$ & 34,7 & 3,107 \\
\hline Índia & 164.3 & 36,9 & 446 \\
\hline Indonésia & 27.3 & 22,2 & 123 \\
\hline Coreia do Sul & 121.1 & 30,4 & 398 \\
\hline Malásia & 14.0 & 14,5 & 97 \\
\hline Filipinas & 40.5 & 52,0 & 78 \\
\hline Taiwan & 199.2 & 41,5 & 480 \\
\hline Tailândia & 96.0 & 43,8 & 219 \\
\hline República Checa & - & - & 123 \\
\hline Hungria & 0.9 & 3,7 & 25 \\
\hline Israel & 45.6 & 35,2 & 129 \\
\hline Polônia & 32.6 & 7,2 & 451 \\
\hline Romênia & 5.8 & 15,2 & 38 \\
\hline Rússia & 10.5 & 2,4 & 440 \\
\hline África do Sul & 13.5 & 28,0 & 48 \\
\hline Turquia & 2.8 & 3,8 & 73 \\
\hline Argentina & 6.7 & 20,0 & 33 \\
\hline Brasil & 283.3 & 81,9 & 346 \\
\hline Chile & 32.5 & 89,7 & 36 \\
\hline Colômbia & 29.7 & 58,3 & 51 \\
\hline México & 45.8 & 25,9 & 177 \\
\hline Peru & 19.8 & 30,3 & 65 \\
\hline Uruguai & 9.4 & 65,0 & 14 \\
\hline
\end{tabular}

Fonte: JP Morgan (2020, p.1).

No entanto, a fragmentação decorrente da ordem monetária global deve ser avaliada com cautela, pois apresenta riscos inerentes. Organizações internacionais são entidades autônomas constituídas com mandato internacional, su- 
pervisionadas por Estados e formadas por funcionários, que devem atuar na coordenação de ações globais. Bancos centrais são autoridades constituídas enquanto agências com mandatos nacionais específicos. Em caso de conflito entre o cumprimento de seu mandato (geralmente, a estabilidade monetária e financeira do sistema local) e a demanda internacional por maior coordenação, a ordem global pode sofrer impacto negativo. A cooperação organizada em torno de autoridades nacionais é discricionária e baseada em convenções mais flexíveis, comparativamente a tratados internacionais.

\section{Conclusão}

O FMI, criado pelo Acordo de Bretton Woods em 1944, foi concebido como a organização multilateral para centralizar a cooperação monetária global e servir como prestamista de última instância para Estados-nação, em tempos de crise. Nas últimas décadas, contudo, o Fundo tornou-se o principal prestamista, sobretudo, a países da periferia do sistema monetário internacional.

Em contraste, no centro do sistema financeiro global, nas crises de 2008 e 2020, o FED e os principais bancos centrais em economias avançadas, em formato de rede, tornaram-se os prestamistas de último recurso para agentes do mercado financeiro global. Essas autoridades monetárias sustentam o funcionamento do mercado do eurodólar, a forma jurídica, por excelência, da moeda internacional.

Em decorrência da crise da Covid-19, a rede de swaps consolidou-se como uma espécie de novo acordo de Bretton Woods, em outros termos políticos e base jurídica. O novo Bretton Woods, que serve para sustentar o funcionamento do dólar americano como moeda internacional, é mais fragmentado. No centro do sistema monetário, a cooperação não é mais centralizada por uma organização multilateral, com mandato global específico. A coordenação de ações coletivas é assegurada por uma rede de autoridades nacionais, que compartilham modelos de política pública e são responsáveis pela gestão da moeda em cada uma das jurisdições participantes.

A rede de swaps é altamente seletiva e elitista: é reservada a autoridades monetárias, que estão localizadas em economias integradas financeiramente e com grau mais elevado de desenvolvimento econômico. A crise mais recente revelou que esse arranjo jurídico de cooperação passa a ser permanente e prioritário para os países membros. Não se trata mais de um recurso simplesmente temporário e paralelo às organizações multilaterais.

No centro do sistema global, o papel dos bancos centrais está mudando a natureza jurídica da cooperação: de organizações internacionais para arranjos contratuais. Esses acordos proporcionam acesso ilimitado a financiamentos, que suportam agentes no mercado de eurodólares.

$\mathrm{O}$ direito tem, assim, papel fundamental na explicação e na constituição desse modelo de cooperação. $\mathrm{O}$ direito privado estrutura as relações financeiras entre agentes econômicos, em âmbito global, por meio dos contratos de euro- 
dólares. O prestamista de último recurso, associado à moeda internacional, é uma rede organizada por contratos entre autoridades públicas nacionais, que são, por natureza, também instituições financeiras e emissores de suas respectivas moedas.

O movimento de contestação do dólar, como moeda internacional, pode eventualmente alterar, em médio ou longo prazo, esse novo Bretton Woods. Por ora, fazer parte da rede de swaps cambiais junto ao FED é sinal de desenvolvimento financeiro e também de certo prestígio, inclusive e especialmente para bancos centrais em economias emergentes, como o Brasil.

\section{Notas}

1 A ideia de que a rede de swaps entre bancos centrais representaria um momento "Bretton Woods" foi vocalizada pela primeira vez por Perry Mehrling, professor da Pardee School of Global Studies da Universidade de Boston, em seu curso sobre economia monetária internacional.

2 Consequentemente, não uso aqui o sentido estrito de moeda, que representa instrumentos que têm o atributo do curso legal (e, geralmente, também curso forçado) no contexto nacional. Moedas estrangeiras são juridicamente moeda, e não mercadoria, apesar de não ter curso legal em outras jurisdições (Proctor, 2012, p.51; De Chiara, 1986).

3 A emergência e a expansão exponencial, a partir de 2008, do uso e das modalidades de criptomoedas podem alterar esse cenário internacional.

4 A expressão foi originalmente empregada por Valéry Giscard d'Estaing, na década de 1960, como ministro das finanças do governo francês de Charles de Gaulle. De Gaulle, em uma série de conferências à imprensa, argumentava que o mundo estava sustentando "o padrão de vida dos americanos e subsidiando suas multinacionais" por meio de um sistema financeiro global assimétrico, centralizado no dólar (tradução livre, Eichengreen, 2011, p.4).

5 Para uma explicação didática sobre o conceito de governança econômica global e suas instituições, ver o verbete "governança econômica global" publicado em Duran (2020a).

6 Os Direitos Especiais de Saque (DES), alocados pelo FMI, representam um ativo financeiro de reserva internacional, um tipo de liquidez incondicional destinada a membros do Departamento do DES. Eles se configuram como reivindicações potenciais de moedas globais, emitidas por outros países membros (como o dólar americano). O DES não é moeda, tampouco um passivo do FMI. Os DES são alocados e não emitidos pelo Fundo. Trata-se, basicamente, de uma linha de crédito entre todos os participantes do Departamento do DES (Lastra, 2015, p.449; Duran, 2015).

7 Existem relatos ligeiramente distintos sobre o primeiro depósito denominado em dólares americanos na Europa (ver, por exemplo, Durden, 2020). Para os determinantes institucionais do surgimento do mercado de eurodólares, como a edição de Regulamentos D e Q pelo FED, e as práticas efetivas de Estados comunistas, que procuravam evitar aplicar suas reservas em dólares no território dos Estados Unidos, ver Békerman (1977); Hirsch; Oppenheimer (1976, p.663-5); Clendenning (1970, p.21-35). 
8 Curso legal é o atributo da moeda, reconhecida por lei, como o meio final para o cumprimento de uma obrigação jurídica.

9 De acordo com o Artigo VIII, Seção 2 (a), do Convênio Constitutivo do FMI, nenhum membro deverá, sem a aprovação do Fundo, impor restrições à realização de pagamentos e transferências de transações internacionais correntes.

10 As obrigações correspondentes estão previstas nos Códigos de Liberalização de Movimento de Capitais e de Operações Correntes Intangíveis. Sobre a estrutura jurídica dos Códigos e as operações financeiras disciplinadas, ver Duran (2020b) e Thorstensen e Gullo (2019).

$11 \mathrm{O}$ banco central chinês, no processo de internacionalização do renminbi, adota a ideia de "conversibilidade gerida" (managed convertibility; Zhou, 2015), impondo certas restrições ao uso de sua moeda. O renminbi conta com uma estrutura de swaps cambiais entre bancos centrais (Duran, 2017a).

12 Mehrling (2015, p.14) explica como se manifesta essa desconfiança em tempos de crise. Há dois principais sintomas do colapso. Primeiro, há um spread significativo e persistente entre as taxas de juros praticadas no mercado do eurodólar e as taxas do mercado financeiro americano. Outro sintoma é a persistência da violação à paridade coberta de juros, que conecta o sistema do eurodólar aos mercados monetários em outras moedas, em tempos de normalidade.

13 A ideia básica era um acordo bilateral pelo qual um banco central abria uma conta em seus livros (e, geralmente, em sua própria moeda) em nome de outro banco central, e vice-versa. Para conter os riscos cambiais, os swaps eram limitados no tempo, geralmente por três meses (Toniolo, 2005, p.386).

14 Originalmente, o seguinte grupo seleto de bancos centrais passaram a integrar, no tempo, a rede de swaps cambiais com o FED: o Banco Nacional Austríaco, o Banco Nacional da Bélgica, o Banco da França, o Banco Federal Alemão, o Banco da Itália, o Banco da Holanda, o Banco Nacional da Dinamarca, o Banco da Inglaterra, o Banco do Japão, o Banco da Noruega, o Banco da Suécia e o Banco Nacional da Suíça.

15 McKinnon (1993) diverge dessa interpretação dos tratados. Para ele, a obrigação não era de conversão, mas meramente referencial de valor. A prática dos acordos de Bretton Woods, contudo, revela a crença na possibilidade jurídica da conversão da moeda em ouro. Naquela época, o economista Charles A. Coombs trabalhava para o Federal Reserve Bank de Nova York e ajudou a projetar o que se tornou o Swap da Basileia. Segundo seu relato, devido ao papel central do dólar como "a moeda de reserva oficial e, consequentemente, a "moeda de transação" dos mercados de câmbio, os Estados Unidos ficaram presos a um padrão bilateral de relações financeiras com cada um dos bancos centrais estrangeiros" (tradução livre, Coombs, 1976, p.74).

16 "Devido à formação do Banco Central Europeu e à luz de 15 anos de desuso, os acordos de swap bilaterais do FED com o Banco Nacional Austríaco, o Banco Nacional da Bélgica, o Banco da França, o Banco Federal Alemão, o Banco da Itália e o Banco da Holanda passaram a ser considerados desnecessários diante das modalidades atuais de cooperação monetária internacional. Assim, as partes concordaram em permitir que eles prescrevessem. Da mesma forma, estabeleceu-se conjuntamente que os acordos de swap bilaterais entre o FED e o Banco Nacional da Dinamarca, o Banco da Inglaterra, o Banco do Japão, o Banco da Noruega, o Banco da Suécia, Banco Nacional da Suíça, e o Banco de Compensações Internacionais fossem desfeitos à luz de seu desuso 
e dos arranjos para a cooperação monetária internacional utilizados hoje" (tradução livre de minuta do FOMC/Fed, datada de 17 de novembro de 1998 e disponível em: <http://www.federalreserve.gov/fomc/minutes/19981117.htm>).

17 A acumulação de perdas no balanço de um banco central não afeta a criação da moeda. Isso não significa, porém, que a demanda pela moeda não estaria comprometida: depende da confiança social na moeda fiduciária e da eventual existência de um substituto. Essa ideia ainda é bastante controversa na literatura sobre bancos centrais. No entanto, numa nota de rodapé de documento público, o Banco Central Europeu reconheceu claramente essa capacidade institucional de bancos centrais (Bunea et al., 2016, p.14, nota 7).

18 A íntegra do documento está disponível em: <https://www.newyorkfed.org/medialibrary/media/markets/USD_Euro_swap_agreement.pdf>.

19 Disponível em: <https://www.federalreserve.gov/newsevents/pressreleases/monetary20131031a.htm>.

20 Comunicado oficial disponível em: <https://www.federalreserve.gov/newsevents/ pressreleases/monetary20200319b.htm>.

21 Declaração disponível em: <https://www.federalreserve.gov/newsevents/pressreleases/fima-repo-facility-faqs.htm $>$.

\section{Referências}

AIZENMAN, J.; JINJARAK, Y.; PARK, D. International reserves and swap lines: substitutes or complements? NBER and Asian Development Bank, Março 2010.

AIZENMAN, J.; PASRICHA, G. K. Selective swap arrangements and the global financial crisis: analysis and interpretation, International Review of Economics and Finance v.19, n.3, 2010.

ALLEN, W.; MOESSNER, R. Central bank co-operation and international liquidity in the financial crisis of 2008-9. LSE Financial Markets Group Paper series 187, 2010.

BÉKERMAN. Les euro-dollars. Paris: PUF, 1977.

BROZ, J. L. The Politics of Rescuing the World's Financial System: The Federal Reserve as a Global Lender of Last Resort. Korean Journal of International Studies, v.13, n.2, p.323-51, 2015.

BUNEA, D. et al. Profit distribution and loss coverage rules for central banks. ECB Occasional Paper, n.169, 2016.

CARRÉ, E.; LE MAUX, L. The Federal Reserve's Dollar Swap Lines and the European Central Bank during the global financial crisis of 2007-2009. In: Symposium on Money, Banking and Finance. 2018.

CARRÉ, E.; LE MAUX, L. The Federal Reserve's Dollar Swap Lines and the European Central Bank during the global financial crisis of 2007-09. Cambridge Journal of Economics, 2020.

CARREAU, D. Souveraineté monétaire et utilisation de la monnaie par les opérateurs privés. In: KAHN, P. (Ed.) Droit et monnaie. Dijon: Litec, 1988. p.399-407. 
CARREAU, D. Le système monétaire international privé (UEM et euromarchés). Martinus Nijhoff, 1998.

CHEY, H. Why Did the US Federal Reserve Unprecedentedly Offer Swap Lines to Emerging Market Economies during the Global Financial Crisis? Can We Expect Them Again in the Future? GRIPS Discussion Paper, n.11-18, 2012.

CLENDENNING, E. W. Euro-dollar market. Oxford University Press, 1970.

COHEN, B. Currency and state power. Back to Basics: State Power in a Contemporary World, 2013.

COHEN, B. J.; BENNEY, T. M. What does the international currency system really look like? Review of International Political Economy, v.21, n.5, 2014.

COOMBS, C. A. The arena of international finance. New York: John Wiley Sons, 1976.

DE CHIARA, José Tadeu. Moeda e ordem jurídica. São Paulo, 1986. Tese (Doutorado) - Faculdade de Direito, Universidade de São Paulo.

DESAN, C. Money as legal institution. In: FOX, D.; WOLFGANG, E. Money in the Western Legal Tradition. Oxford: Oxford University Press, 2014.

DURAN, C. V. Avoiding the next liquidity crunch: how the G20 must support monetary cooperation to increase resilience to crisis. GEG / BSG policy brief, University of Oxford, October 2015.

O Prestamista internacional de última instância para países emergentes: um contrato de swap cambial? Revista Tempo do Mundo IPEA, 2017a.

Monetary Policy: Making Fragmentation Work. In: DALE, T.; HELD, D. Beyond Gridlock. S. 1.: John Wiley \& Sons, 2017b.

Voice and exit: How emerging powers are promoting institutional changes in the international monetary system. Braz. J. Int'l L., v.15, p.71, 2018.

Governança econômica global. In: ANETE, I. B. L. (Coord.) Dicionário temático Desenvolvimento e Questão Social. 2.ed. São Paulo: Annablume, 2020a.

Ser membro da OCDE: é um caminho para o Brasil responder a crises futuras? Nota Técnica NEPEI n.l, Instituto de Relações Internacionais, USP, Junho de 2020b.

DURDEN, T. "Down The Rabbit Hole" - The Eurodollar Market Is The Matrix Behind It All, website Medium, 19 de abril de 2020. Disponível em: <https://medium.com/@tlmproject/down-the-rabbit-hole-the-eurodollar-market-is-the-matrix-behind-it-all-a7a054dd4b0f>.

EICHENGREEN, B. Exorbitant privilege: the rise and the fall of the dollar and the future of the International Monetary System. Oxford: Oxford University Press, 2011.

GOLD, J. Legal and Institutional Aspects of the International Monetary System: Selected Essays (v. II). International Monetary Fund, 1984.

HAAS, P. M. Introduction: epistemic communities and international policy coordination. International Organization 46(1), Knowledge, Power, and International Policy Coordination, 1992.

HAWTREY, R. G. The Art of Central Banking. London: s. n., 1932.

HELLEINER. Political determinants of international currencies: what future for the US dollar? Review of International Political Economy, v.15, n.3, 2008. 
HENNING, C. R. The global liquidity safety net: institutional cooperation on precautionary facilities and central bank swaps, CIGI paper n.5, Março de 2015.

HIRSCH, F. Money international. Allen Lane The Penguin Press, 1967.

HIRSCH, F.; OPPENHEIMER, P. The trial of managed money: currency, credit and prices 1920-1970. The Fontana Economic History of Europe, v.5, 1976.

HODGSON, G. M. Conceptualizing capitalism: Institutions, evolution, future. University of Chicago Press, 2015.

KINDLEBERGER, C. The eurodollar and the internationalization of United States' monetary policy. Reprinted in C. Kindleberger, International Money (1981), p.100-10. 1969.

The world in depression 1929-1939. Berkeley; Los Angeles: University of California Press, 2012.

KINDlEBERGER, C.; ALIBER, Z. R. Manias, Panics, and Crashes: A History of Financial Crises. Nova York: Palgrave Macmillan, 2011.

KIRSHNER, J. Bringing them all back home? dollar diminution and US power. The Washington Quarterly, v.36, n.3, p.27-45, 2013.

LASTRA, R. M. Legal Foundations of International Monetary Stability. Oxford: Oxford University Press, Oxford, 2015.

McDOWELL, D. The US as 'sovereign international last-resort lender': the Fed's currency swap programme during the great panic of 2007-2009. New Political Economy, v.17, n.2, 2012 .

Emergent international liquidity agreements: central bank cooperation after the global financial crisis. Journal of International Relations and Development, v.22, n.2, 2019. p.441-467.

McKINNON, R. Private and official international money: the case for the dollar. International Finance Section. Department of Economics. Princeton University, 1969.

. The eurocurrency market. International Finance Section, Department of Economics, Princeton University, 1977.

The Rules of the Game: International Money in Historical Perspective. Journal of Economic Literature, v.31, 1993.

MEHRLING, P. Elasticity and discipline in the global swap network. Working paper for the conference 'China and the global financial system', Shangai Development Research Foundation, August 2015.

MOESSNER, R.; ALLEN, W. Banking crises and the international monetary system in the Great Depression and now. BIS paper 333, 2010.

MORGAN, J. P. Fed repo gives some extra help to EM central banks. Global Emerging Markets Research, 31 de março de 2020.

NORRLOF, C. Dollar hegemony: A power analysis. Review of International Political Economy, v.21, n.5, p.1042-70, 2014.

OTERO-IGLESIAS, M.; STEINBERG, F. Is the dollar becoming a negotiated currency? Evidence from the emerging markets. New Political Economy, v.18, n.3, 2013. 
PANETTA, F.; SCHNABEL, I. The provision of euro liquidity through the ECB's swap and repo operations. The ECB Blog, 19 de agosto de 2020. Disponível em: <https:// www.ecb.europa.eu/press/blog/date/2020/html/ecb.blog200819 0dld04504a. en.html>.

PISTOR, K. A legal theory of finance. Journal of Comparative Economics, v.41, n.2, p.315-330, 2013.

n.2, 2017

From Territorial to Monetary Sovereignty. Theoretical Inquiries in Law, v.18,

PRASAD, Eswar S. Gaining currency: the rise of the renminbi. Oxford: Oxford University Press, 2017.

PROCTOR, C. Mann on the Legal Aspect of Money. 7.ed. Oxford: Oxford Press, 2012.

STRANGE, S. The politics of international currencies. World Politics, v.23, n.2, 1971.

THORSTENSEN, V. H; GULLO, M. F. OCDE e os códigos de capitais e intangíveis: código de liberalização de movimento de capitais e código de operações correntes intangíveis. Working paper, Biblioteca digital FGV, São Paulo, 2019.

TONIOLO, G. Central bank cooperation at the Bank for International Settlements, 1930-1973. Cambridge University Press, 2005.

ZHOU, X. Statement by the Honorable Zhou Xiaochuan Governor of the IMF for China to the Thirty-First Meeting of the International Monetary and Financial Committee Washington, DC. Washington, DC: International Monetary Fund, 2015.

ZIMMERMMAN, C. D. The Concept of Monetary Sovereignty Revisited. European Journal of International Law, v.24, issue 3, l August 2013.

RESUMO - A crise da Covid-19 reforçou e consolidou um modelo de cooperação monetária global que visa sustentar o funcionamento do mercado financeiro internacional. No centro do sistema monetário, o desenho jurídico para a cooperação tem se alterado substancialmente: da centralidade de ações coletivas coordenadas por organizações multilaterais (como o Fundo Monetário Internacional, o FMI), para mecanismos contratuais mais flexíveis, formalizados por bancos centrais e sua rede de swaps cambiais. A gestão dos impactos monetários da crise da Covid-19 revela um novo momento Bretton Woods, que recorre a outros termos políticos e jurídicos para estruturar as relações internacionais. $\mathrm{O}$ argumento deste artigo é o de que o direito tem papel explicativo e constitutivo dessa mudança. O dólar americano, como moeda internacional, é estruturado por um tipo específico de contrato, o eurodólar. Em tempos de crise, esse contrato demanda um prestamista internacional de última instância, capaz de conceder, de forma ilimitada, suporte aos usos globais da moeda. Somente uma instituição financeira, organizada como banco central, tem a capacidade jurídica e econômica de desempenhar esse papel - e não um fundo multilateral. A rede hierárquica de swaps cambiais, com o banco central americano (Federal Reserve, o Fed) em seu topo, foi o arranjo jurídico estruturado para sustentar o funcionamento do mercado financeiro global e de sua moeda por excelência, o eurodólar.

PALAVRAS-CHAVE: Fundo Monetário Internacional (FMI), Bancos centrais, Federal Reserve (FED), Cooperação monetária internacional, Swaps cambiais. 
ABSTRACT - The Covid-19 crisis reinforced and consolidated a template for global monetary cooperation, aiming to keep the international financial markets functioning. At the core of the monetary system, the legal design for cooperation has changed substantially: from the central role of multilateral organizations responsible for organizing collective actions (such as the International Monetary Fund - IMF), to more flexible contractual arrangements, formalized by a network of Central Bank swaps. The management of the Covid-19 monetary impacts reveals a new Bretton Woods moment, organized in novel political and legal terms. This article argues that Law has an explanatory and constitutive role in this substantial development. The US dollar, as a global currency, is structured by a specific type of contract, the eurodollar. In times of crisis, this contract requires an international lender of last resort that provides unlimited financial support to the currency's global uses. Only a financial institution organized as a central bank has the legal and economic capacity to perform this role - not a multilateral fund. The hierarchical network of Central Bank swaps, with the American Central Bank (the Federal Reserve - Fed) at the top, was the legal arrangement structured to support the functioning of the global financial market and its currency par excellence, the eurodollar.

KEYWORDS: International Monetary Fund (IMF), Central Banks, Federal Reserve (FED), Global monetary cooperation, Central Bank swaps.

Camila Villard Duran é professora da Faculdade de Direito da Universidade de São Paulo; pesquisadora associada ao Instituto de Estudos Avançados (IEA) de Nantes; pesquisadora sênior do Global Economic Governance Programme da Universidade de Oxford; pesquisadora pós-doutora pelas Universidades de Oxford e Princeton. É doutora em direito pelas Universidades de São Paulo e Paris 1 Panthéon-Sorbonne.

@ - camiladuran@usp.br / https://orcid.org/0000-0002-8251-1052.

Recebido em $1^{\circ} .10 .2020$ e aceito em 6.10.2020.

${ }^{\text {I }}$ Faculdade de Direito, Universidade de São Paulo, São Paulo, Brasil. 